STUDI

FRANCESI

\section{Studi Francesi}

Rivista quadrimestrale fondata da Franco Simone

180 (LX | III) | 2016

Varia

\title{
Hanan Hashem, Émile Augier, Alexandre Dumas fils, Victorien Sardou. Dramaturgie du savoir-vivre sous le Second Empire
}

\section{Valentina Ponzetto}

\section{(2) OpenEdition \\ Journals}

Édition électronique

URL : http://journals.openedition.org/studifrancesi/5363

DOI : 10.4000/studifrancesi.5363

ISSN : 2427-5856

Éditeur

Rosenberg \& Sellier

\section{Édition imprimée}

Date de publication : 1 décembre 2016

Pagination : 538-539

ISSN : 0039-2944

\section{Référence électronique}

Valentina Ponzetto, "Hanan Hashem, Émile Augier, Alexandre Dumas fils, Victorien Sardou. Dramaturgie du savoir-vivre sous le Second Empire », Studi Francesi [En ligne], 180 (LX | III) | 2016, mis en ligne le 01 janvier 2017, consulté le 18 septembre 2020. URL : http://journals.openedition.org/studifrancesi/5363 ; DOI : https://doi.org/10.4000/studifrancesi.5363

Ce document a été généré automatiquement le 18 septembre 2020.

\section{cc) (†) $\odot$}

Studi Francesi è distribuita con Licenza Creative Commons Attribuzione - Non commerciale - Non opere derivate 4.0 Internazionale. 


\title{
Hanan Hashem, Émile Augier, Alexandre Dumas fils, Victorien Sardou. Dramaturgie du savoir-vivre sous le Second Empire
}

\author{
Valentina Ponzetto
}

\section{RÉFÉRENCE}

HANAN HASHEM, Émile Augier, Alexandre Dumas fils, Victorien Sardou. Dramaturgie du savoirvivre sous le Second Empire, Paris, L'Harmattan, 2015, 285 pp.

1 Sous le Second Empire, la triade - certains aiment dire «trinité»- Augier-Dumas filsSardou, trône au sommet de la hiérarchie dramatique et des succès de public. «L'habitude est prise de les évoquer conjointement, comme symbole à la fois de la comédie "moderne" ou "sociale" et [...] comme illustration du théâtre officiel», écrit à propos d'eux Jean-Caude Yon (Une triade et un vétéran: Augier-Dumas fils-Sardou et Scribe sous le Second Empire, in Les Spectacles sous le Second Empire, Armand Colin, 2010, p. 126). De nos jours, cependant, ils ne sont plus guère joués, et restent globalement assez peu étudiés. Rares sont les critiques qui s'y consacrent, avec les exceptions notables de Lise Sabourin pour Dumas fils et Isabelle Moindrot pour Sardou, encore plus rares ceux qui décident de les évoquer ensemble, renouvelant avec les yeux d'aujourd'hui des associations critiques établies au XIXe siècle. On ne saurait donc saluer qu'avec intérêt cette étude sur la Dramaturgie du savoir-vivre sous le Second Empire chez nos trois auteurs proposée par Hanan Hashem, issue de la thèse de doctorat de son auteure.

2 Une surprise, toutefois, attend le lecteur dès les pages de l'introduction: le corpus retenu ne comprend qu'une vingtaine de pièces, à savoir «les principales comédies en prose» des trois auteurs, sans que soient établis des critères vraiment convaincants d'inclusion ou d'exclusion des œuvres. Or, si le choix d'exclure les drames historiques 
de Sardou et la Diane de Lys de Dumas apparaît naturel, l'auteure s'intéressant aux représentations du savoir-vivre Second Empire, d'autres critères semblent plus douteux. Par exemple l'exclusion des comédies en vers d'Augier sous prétexte qu'il est «le seul, parmi ses pairs, à s'être aventuré dans la versification dramatique» (p. 14). Ou encore celle de la célébrissime Dame aux camélias de Dumas simplement parce qu'il s'agit d'un drame, alors que Le Mariage d'olympe d'Augier est pris en compte, que l'analyse fera la part belle aux personnages féminins de demi-mondaines et autres filles entretenues et que la question du genre de la comédie ou du registre comique n'est jamais vraiment posée dans l'ouvrage, mais seulement traitée au passage pour commenter un effet de scène. Enfin on se demandera pourquoi pour Sardou un choix de «ses comédies les plus réussies» aurait été «nécessaire» «par souci d'homogénéité de l'ensemble du corpus» (p. 15).

L'approche critique choisie pour aborder le corpus retenu est celle de la sociopoétique dans la lignée d'Alain Montandon, c'est-à-dire «l'étude de l'inscription dans l'écriture des représentations de l'imaginaire de l'interaction sociale» (p.16). S'inspirant des études du critique sur la politesse et le savoir-vivre, l'auteure propose un portrait du savoir-vivre de la bourgeoisie du Second Empire tel qu'il émerge des pièces retenues.

L'étude est divisée en deux parties, «Esthétique théâtrale du savoir-vivre», qui traite des lieux, des personnages et des ressorts dramatiques offerts par les échanges épistolaires de toute sorte, et «Caractère spectaculaire du savoir-vivre», qui passe en revue une foule de savoureux détails de la vie mondaine: postures et gestes des personnages, habits et accessoires, arts de la table. Plus attendue et classique, la première partie propose d'abord l'opposition traditionnelle et incontournable entre Paris et la province, puis une longue galerie de personnages: les protagonistes féminines, classées dans une échelle descendante de rang social de la «dame comme il faut» à la demi-mondaine, véritable vedette du théâtre du temps; les protagonistes masculins, aristocrates, bourgeois, gentlemen et dandys; enfin les domestiques des deux sexes, classés soit selon leur rôle (gouvernante, duègne, portier), soit selon leurs vices ou vertus et leur attitude plus ou moins respectueuse envers leurs maîtres.

Plus intéressante et originale se révèle l'étude des relations mondaines et de la mise en scène de soi que celles-ci comportent. On appréciera ainsi l'évocation des rituels de la visite mondaine ou des codes qui gèrent les échanges par écrit (de la provocation en duel au billet doux, sans oublier la nouvelle mode de la carte de visite), ainsi que les gestes de la politesse, avec, par exemple, une fine analyse de l'opposition entre baisemain et shake-hand à l'anglaise, dont l'emploi peut servir dans les pièces à révéler le caractère ou les relations réciproques des personnages. Particulièrement réussies, les parties consacrées aux «toilettes tapageuses» et aux arts de la table analysent une foule de menus détails qui sont à la fois témoignages des pratiques du savoir-vivre du temps et ressorts dramaturgiques de l'intrigue. Pour ne citer que quelques exemples, la question du fard nous renseigne sur des techniques de maquillage en même temps qu'elle soulève des questions morales; l'évocation des bijoux, des dentelles ou du linge de corps sont à la fois document historique, dénonciation des dangers et des dérives de la mode et du luxe, instrument de caractérisation des personnages et parfois éléments moteurs de l'intrigue. Et encore, les références à l'étiquette de table, aux mets et aux boissons servies sont autant d'aperçus sur la bonne société du Second Empire que de véritables enjeux dramatiques. 
6 A posteriori, on pourra regretter que cette complexité et cette double dimension de témoignage d'une époque et de ressort dramaturgique ne soit pas mieux mise en valeur dans tout l'ouvrage. Il est également dommage que les textes soient trop souvent pris au premier degré, comme témoignage brut, sans grand effort de contextualisation, ni véritable prise en compte de leur statut d'œuvres dramatiques ou des différences entre leurs trois auteurs. On aurait pu souhaiter, par exemple, plus de références à d'autres témoignages littéraires contemporains, rarissimes dans ce volume (deux renvois aux Français peints par eux-mêmes à propos de «la lionne», p. 63, et de la pairie, p. 167; un à l' Éloge du maquillage de Baudelaire p. 212). Il est vrai que la bibliographie n'est pas le point fort du livre. On s'étonne, par exemple, de voir systématiquement cité comme référence un ouvrage "grand public» comme le Trésor de la politesse française de Sylvie Weil plutôt que les travaux d'Alain Montandon ou les nombreux manuels de civilité et de savoir-vivre qui fleurissent au $\mathrm{XIX}^{\mathrm{e}}$ siècle. On pourra regretter encore que les différences entre Dumas, Augier et Sardou ne soient prises en considération que brièvement dans la conclusion de l'ouvrage, où Hanan Hashem propose en revanche des pistes possibles pour ses futures recherches.

7 Dans l'ensemble, l'ouvrage, de structure un peu scolaire, se dénonce clairement comme une thèse probablement peu ou prou remaniée par rapport à sa version de soutenance, et qui aurait profité d'un travail plus approfondi de révision. Il reste une lecture curieuse, par moments agréable, qui a le mérite de nous faire redécouvrir des textes et des usages aujourd'hui oubliés. 